\title{
The correlation between preoperative erythrocyte sedimentation rate and postoperative outcome in adult cardiac surgery
}

This article was published in the following Dove Press journal:

International Journal of General Medicine

II January 2017

Number of times this article has been viewed

\author{
Eissa Bilehjani' \\ Solmaz Fakhari' \\ Haleh Farzin' \\ Alireza Yaghoubi ${ }^{2}$ \\ Moussa Mirinazhad' \\ Kamran Shadvar' \\ Abbasali Dehghani' \\ Pariasadat Aboalaiy'
}

'Department of Anesthesiology, Tabriz University of Medical Sciences, Tabriz, ${ }^{2}$ Department of Cardiovascular Surgery, Iran University of Medical Sciences, Tehran, Iran
Correspondence: Solmaz Fakhari

Cardiovascular Research Center, Madani Heart Hospital, Tabriz University of Medical Sciences, Daneshgah Street, Tabriz 5I666I5573, Iran

Tel +989141160647

Fax +98 4II 3373950

Email solmaz_fakhari@yahoo.com
Introduction: Over the past decades, it has been recommended that preoperative assessment mainly relies on history and physical examination rather than unnecessary laboratory tests. In Iranian hospitals, erythrocyte sedimentation rate (ESR) has been routinely measured in most of the patients awaiting major surgery, which has in turn exacted heavy costs on the health system. Therefore, the aim of the present study was to assess the preoperative routine measurement of ESR in such patients.

Materials and methods: This is a retrospective study, in which we evaluated the medical files of 620 patients. Patients older than 18 years, who had undergone elective heart surgery in our hospital in 2014, were included in the study. The data associated with demography, heart disease diagnosis, type of surgery, significant preoperative tests, delay or postponing of surgery and the reason for it, type and characteristics of the subspecialty consultation, and finally, postoperative complication and mortality rate were collected and analyzed. The patients were categorized into four groups according to ESR value: normal ( $<15 \mathrm{~mm} / \mathrm{h}$ in females or $<20 \mathrm{~mm} / \mathrm{h}$ in males), moderately increased $(<40 \mathrm{~mm} / \mathrm{h})$, severely increased $(\geq 40 \mathrm{~mm} / \mathrm{h})$, and not measured.

Results: Of the 620 patients' files, 402 were of males and 218 were of females. Demographic values and preoperative characteristics were similar in the four groups. A total of 105 consultations were given to 79 patients preoperatively, where only in five cases, the elevation in ESR was the main reason for consultation. In no other cases did the consultations result in new diagnoses. Overall, postoperative complication and mortality rate were the same in all four groups; in severely increased ESR group, on the other hand, the need for long periods of intensive care unit (ICU) and hospital stays was higher than that of other groups.

Conclusion: It is concluded that elevated preoperative ESR does not cancel or defer the surgery, nor does it help diagnose a new, previously undiagnosed disease. Furthermore, it does not generally affect postoperative morbidity or mortality rate unless increased to $\geq 40 \mathrm{~mm} / \mathrm{h}$, where it can increase postoperative ICU and hospital stay. Ultimately, routine preoperative ESR measurement in patients is not conducive to elective heart surgery.

Keywords: erythrocyte sedimentation rate, heart surgery, postoperative complication, postoperative mortality

\section{Introduction}

There exists a myriad of modalities to optimize the preoperative status and reduce the postoperative complications. ${ }^{1-3}$ Physical examination, basic laboratory tests (complete blood count, blood sugar (BS), Na, K, blood urea nitrogen (BUN), creatinine, prothrombin time (pt), partial thromboplastin time (ptt), erythrocyte sedimentation rate (ESR) and C-reactive protein [CRP]), chest X-ray, echocardiography, electrocardiography 
and often Cath Lab investigation were routinely performed in every adult candidate of elective cardiac surgery. The patient was considered acceptable for evaluation when the last four modalities have been performed in the last 6-12-month period. In carotid artery color Doppler study, urinary analysis was done rarely in selected patients. Erythrocyte sedimentation rate (ESR) is a cheap, routine and facile-to-carry out preoperative test, ${ }^{4}$ which is routinely performed in many health centers in patients admitted for surgery. Nonetheless, the worth of this test has not been specified yet ${ }^{5}$ or whether it is a reliable predictor of mortality or morbidity following heart surgery. We usually perform the tests that can help us to predict the important variables influencing intensive care unit (ICU) stay, hospital stay time and postoperative complications. Such tests are defined more by their cost, sensitivity, specificity and availability. ESR, not infrequently, reflects the inflammatory status of patients, and owing to the recently defined inflammatory processes involved in the development of cardiac disease, certain studies have reported its prediction value and association with postprocedure complications. ${ }^{6,7}$ Gillum et $\mathrm{al}^{8}$ reported the predictive value of ESR in coronary artery diseases. Andresdottir et $\mathrm{al}^{9}$ found the same results for ESR in their study. Ozlu et $\mathrm{al}^{10}$ showed that elevated ESR is related to poor short- and long-term prognosis in patients who are candidates of primary percutaneous coronary artery revascularization. Furthermore, Erikssen et al ${ }^{11}$ observed a strong correlation between increased ESR and coronary artery disease and its mortality rate. Togan et $\mathrm{al}^{7}$ recently reported that preoperative elevation of ESR is a risk factor for the postcoronary artery bypass graft (post-CABG) complication in male patients. Similarly, Parolari et al ${ }^{12}$ stated that increased levels of other similar biomarkers such as IL-1 and CRP are associated with the unfavorable outcome following CABG. The primary purpose of the present study was to investigate the relationship between elevated levels of preoperative ESR and short- and mid-term outcome and postoperative complications in adult heart operations. The second objective was to clarify the role of increased ESR in optimizing the preoperative status.

\section{Materials and methods}

This study is a descriptive retrospective study approved by the ethics committee of Research Deputy of Tabriz University of Medical Sciences which does not require patient consent to review the medical files for large retrospective studies. The study included 642 adult patients who underwent elective cardiac surgery in Shahid Madani Heart Center. The medical files of the patients older than 18 years of age who were scheduled for elective cardiac surgery during 2014 were included. The medical files with emergent surgeries, not ended in cardiac surgery, and with malignant, infectious, inflammatory or rheumatic diseases, renal insufficiency, brain damage as well as incomplete documents were excluded. Following a pilot study of 20 files, the final data collection form was prepared. Anesthesiologists, working in the cardiovascular anesthesia field as academic members, collected the preoperative and postoperative data. Preoperative data such as demographic characteristics, type of surgery, left ventricular ejection fraction, smoking habit, comorbid diseases, history of recent myocardial infarction, preoperative angina pectoris, diabetes mellitus, body temperature, laboratory tests including hematocrit, platelet count, white blood cell count, serum creatinine, serum CRP and any hiatus between the first visit by anesthesiologist and the operation time were collected. The following aspects of preoperative subspecialty consultation were further studied: the subspecialty type and reason for consultation, any postconsultation deferring or canceling of the surgery and any newly diagnosed disease due to preoperative consolatory activity. Moreover, we recorded the time period of postoperative ventilatory support and ICU and postoperative hospital stay. Postoperative complications (related to patients' files) were as follows: cardiac (arrhythmias, hemodynamically unstable condition that required inotropic support for a minimum of 2 hours in ICU), respiratory (that required mechanical ventilation for $>24$ hours and reintubation due to respiratory failure, pulmonary infection and pulmonary thromboembolism), renal (anuria or oliguria for $>24$ hours, any serum creatinine level $>2 \mathrm{mg} / \mathrm{dL}$, which required dialysis), ICU admission with open sternum, bleeding $>1000 \mathrm{~mL} / 24 \mathrm{~h}$ or the need for bleeding control surgery, neurologic (cerebrovascular accident [CVA], agitation, delirium, hallucination and psychosis), infections (fever, sepsis and mediastinitis), deep vein thrombosis, jaundice, epistaxis, long ICU ( $>4$ days) or long postoperative hospital stay ( $>10$ days).

Based on the preoperative ESR value, patients were classified into four groups:

Group 1 (normal value): An ESR value of $<15 \mathrm{~mm} / \mathrm{h}$ in female patients or $20 \mathrm{~mm} / \mathrm{h}$ in male patients.

Group 2 (moderately increased): An ESR value of $<40 \mathrm{~mm} / \mathrm{h}$ in male or female patients.

Group 3 (severely increased): An ESR value of $\geq 40 \mathrm{~mm} / \mathrm{h}$ in male and female patients.

Group 4 (not measured): ESR not measured.

\section{Statistical analysis}

The collected data, presented as frequency (percentage) or mean $\pm \mathrm{SD}$, were analyzed using SPSS software Version 16.0. The Kolmogorov-Smirnov test was used to control 
Table I The presentation of the frequency (percentage) of four preoperative ESR groups

\begin{tabular}{ll}
\hline ESR group & $\mathbf{n}(\%)$ \\
\hline ESR not measured & $58(9.4)$ \\
ESR measured* & \\
Normal value & $397(64)$ \\
Moderately increased & $116(18.7)$ \\
Severely increased & $49(7.9)$ \\
Total & $620(100)$ \\
\hline
\end{tabular}

Notes: *Normal value: ESR value $<15 \mathrm{~mm} / \mathrm{h}$ or $<20 \mathrm{~mm} / \mathrm{h}$ in female or male patients, respectively; moderately increased: ESR value $<40 \mathrm{~mm} / \mathrm{h}$; severely increased: ESR value $\geq 40 \mathrm{~mm} / \mathrm{h}$.

Abbreviation: ESR, erythrocyte sedimentation rate.

the distribution normality of the parametric data. Due to parametric data with normal distribution, one-way analysis of variance (ANOVA) test was employed in order to compare the ESR groups with one another. The Kruskal-Wallis test was used for the comparison of categorical data. In addition, Pearson's correlation test was used to assess the association between various complications and ESR levels. All comparisons were performed considering two-tailed tests. Ultimately, $P$-values $<0.05$ were considered statistically significant.

\section{Results}

A total of 620 patients were enrolled for data analysis. Twentytwo patients were excluded from the study due to incomplete data collection, emergent surgeries or hospitalizations not ending in cardiac surgery. Most patients were males (402 male vs. 218 female patients). Preoperatively, ESR was measured in $90.6 \%$ of the patients (562 cases), where it was normal, moderately increased or severely increased in 397 (70.1\%), $116(20.2 \%)$ and $49(8.7 \%)$ patients, respectively (Table 1). There was no significant difference between the four groups with regard to gender, age, weight or height (Table 2). Diabetes mellitus prevalence, smoking habit, rate of preoperative angina pectoris, recent preoperative myocardial infarction and left ventricular ejection fraction were similar in all groups. The most common surgery was coronary artery bypass grafting. The requirement of postoperative ventilatory support was the same in each group; nevertheless, the postoperative ICU and hospital stay period was longer in patients with severely increased preoperative ESR (Table 2). The ESR and plasma CRP tests were simultaneously performed in 404 patients. There existed no correlation between these two tests $(P$-value $=0.133)$.

Table 2 Pre and postoperative characteristics of the four preoperative ESR groups

\begin{tabular}{|c|c|c|c|c|c|c|}
\hline \multirow[t]{2}{*}{ Characteristic } & \multicolumn{6}{|c|}{ Preoperative ESR* } \\
\hline & $\begin{array}{l}\text { Normal value } \\
(n=397)\end{array}$ & $\begin{array}{l}\text { Moderately } \\
\text { increased }(n=116)\end{array}$ & $\begin{array}{l}\text { Severely } \\
\text { increased }(n=49)\end{array}$ & $\begin{array}{l}\text { Not measured } \\
(n=58)\end{array}$ & $\begin{array}{l}\text { Total } \\
(n=620)\end{array}$ & $P$-value \\
\hline Male/female & $260 / 137$ & $73 / 43$ & $32 / 17$ & $37 / 21$ & $402 / 218$ & 0.96 \\
\hline Age (years; mean $\pm S D$ ) & $57.46 \pm 13.53$ & $57.41 \pm 12.86$ & $55.29 \pm 12.27$ & $60.21 \pm 9.53$ & $57.54 \pm 13.00$ & 0.27 \\
\hline Weight (kg; mean $\pm \mathrm{SD})$ & $71.55 \pm 12.53$ & $72.35 \pm 13.59$ & $71.44 \pm 12.46$ & $73.39 \pm 12.48$ & $71.86 \pm 12.71$ & 0.72 \\
\hline Height (cm; mean $\pm S D)$ & $164.94 \pm 7.89$ & $163.85 \pm 8.04$ & $164.17 \pm 8.56$ & $\mid 65.31 \pm 8.36$ & $|64.7| \pm 8.02$ & 0.53 \\
\hline Diabetes mellitus, n (\%) & $64(17.4)$ & $21(18.1)$ & $8(16.3)$ & $9(15.5)$ & $102(16.5)$ & 0.96 \\
\hline Cigarette smoking, n (\%) & $140(35.3)$ & $46(39.6)$ & $19(38.8)$ & $15(25.9)$ & $220(35.5)$ & 0.33 \\
\hline Preoperative angina pectoris, $\mathrm{n}(\%)$ & $282(71.0)$ & $89(76.7)$ & $40(81.6)$ & $47(81.0)$ & 458 (73.9) & 0.16 \\
\hline \multicolumn{7}{|l|}{ infarction, n (\%) } \\
\hline Left ventricle ejection fraction & $46.2 \pm 9.3$ & $46.1 \pm 8.5$ & $46.7 \pm 9.6$ & $47.2 \pm 8.0$ & $46.3 \pm 9.1$ & 0.862 \\
\hline Sublingual temperature (mean $\pm S D$ ) & $36.7 \pm 0.36$ & $36.7 \pm 0.33$ & $36.5 \pm 0.40$ & $36.6 \pm 0.33$ & $36.7 \pm 0.35$ & 0.103 \\
\hline Hematocrit\% (mean $\pm S D)$ & $42.3 \pm 5.4$ & $39.1 \pm 4.9$ & $35.9 \pm 5.5$ & $39.8 \pm 4.8$ & $40.9 \pm 5.6$ & 0.001 \\
\hline Platelet $\times 10^{3} / \mathrm{mm}^{3}($ mean $\pm S D)$ & $209 \pm 62$ & $229 \pm 58$ & $248 \pm 84$ & $223 \pm 77$ & $217 \pm 66$ & 0.001 \\
\hline White blood cell $\times 10^{3} / \mathrm{mm}^{3}($ mean $\pm \mathrm{SD})$ & $7.4 \pm 2.3$ & $7.6 \pm 2.1$ & $8.7 \pm 4.0$ & $9.0 \pm 3.6$ & $7.7 \pm 2.6$ & 0.001 \\
\hline Serum creatinine, $\mathrm{mg} / \mathrm{dL}($ mean $\pm \mathrm{SD})$ & $0.96 \pm 0.47$ & $1.07 \pm 0.72$ & $1.42 \pm 1.48$ & $1.34 \pm 1.67$ & $1.05 \pm 0.83$ & 0.001 \\
\hline C-Reactive protein, $\mathrm{mg} / \mathrm{L}($ mean $\pm \mathrm{SD})$ & $42.57 \pm 102.69$ & $25.42 \pm 82.76$ & $23.32 \pm 78.94$ & $11.41 \pm 51.22$ & $35.23 \pm 94.44$ & 0.133 \\
\hline \multicolumn{7}{|l|}{ Type of surgery } \\
\hline CABG, n (\%) & $300(75.6)$ & $94(81.0)$ & $40(81.6)$ & $47(81.0)$ & $481(77.6)$ & 0.929 \\
\hline Valvular, n (\%) & $38(9.6)$ & $5(4.3)$ & $4(8.2)$ & $8(13.8)$ & $55(8.9)$ & \\
\hline CABG/valvular, n (\%) & $29(7.3)$ & $6(5.2)$ & $2(4.1)$ & $2(3.4)$ & $39(6.3)$ & \\
\hline Others, n (\%) & $30(7.5)$ & II (9.5) & $3(6.1)$ & $\mathrm{I}(\mathrm{I} .8)$ & $45(7.2)$ & \\
\hline Using CPB, n (\%) & $281(70.8)$ & $73(62.9)$ & $35(7 \mathrm{I} .4)$ & $34(58.6)$ & $423(68.2)$ & 0.418 \\
\hline Ventilatory support (hours) & $19.6 \pm 1.2$ & $18.2 \pm 2.1$ & $25.3 \pm 4.7$ & $21.0 \pm 3.7$ & $19.9 \pm 2.9$ & 0.399 \\
\hline ICU stay (days) & $4.2 \pm 0.2$ & $4.2 \pm 0.3$ & $6.4 \pm 0.9$ & $4.8 \pm 0,6$ & $4.4 \pm 0.5$ & 0.003 \\
\hline Hospital stay (days) & $7.9 \pm 0.3$ & $8.0 \pm 0.6$ & $10.5 \pm 1.0$ & $8.7 \pm 0.07$ & $8.2 \pm 0.7$ & 0.023 \\
\hline
\end{tabular}

Notes: *Normal value: ESR value $<15 \mathrm{~mm} / \mathrm{h}$ or $<20 \mathrm{~mm} / \mathrm{h}$ in female or male patients, respectively; moderately increased: ESR value $<40 \mathrm{~mm} / \mathrm{h}$; severely increased: ESR value $\geq 40 \mathrm{~mm} / \mathrm{h}$.

Abbreviations: ESR, erythrocyte sedimentation rate; CABG, coronary arteries bypass graft surgery; CPB, cardiopulmonary bypass; ICU, intensive care unit. 
Totally, 105 subspecialty consultations were given preoperatively. These consultations were given to 79 patients $(12.7 \%)$, where merely in five patients $(4.8 \%$ of all consultations), the consultation was due to elevated ESR levels. Only in two cases, the consultation was due to high CRP levels. Neurologic, infectious, respiratory, endocrinologic and nephrologic subspecialties were the most common subjects of consultations, respectively. The most common reasons for consultation were impaired renal tests, leukocytosis, high blood sugar level and history of CVA. Surgery was postponed for only 20 patients with the purpose of optimizing patient status or conducting further diagnostic tests. The consultations did not lead to any newly diagnosed diseases. In the consulted subjects, the complication and mortality rate were higher than in nonconsulters $(70.5 \%$ vs.
$52.6 \%, P$-value $<0.001$ and $17.1 \%$ vs. $5.2 \%, P$-value $<0.001$, respectively). Deferring the elective surgery for consulters (for further evaluation) did not have any additional benefit. Elevated ESR or CRP levels did not have any influence on the delayed or postponed surgery. Table 3 shows the postoperative morbidity and mortality rates where, as seen, the mortality and overall postoperative complication rates are similar in all groups; the need for long ICU or hospital stay, on the other hand, is higher in severely increased ESR group than the normal value or moderately increased groups ( $P$-value $<0.01)$. Left ventricular ejection fraction (LVEF) was low in patients who were not discharged from the hospital $(40.3 \% \pm 10.03 \%$ vs. $46.8 \% \pm 4.85 \%, P$-value $=0.001$ ). Table 4 illustrates the relationship between postoperative complications and mortality rate with various CRP

Table 3 Postoperative complication and mortality rate due to preoperative ESR

\begin{tabular}{|c|c|c|c|c|c|c|}
\hline \multirow[t]{2}{*}{ Complication } & \multicolumn{6}{|c|}{ Preoperative ESR* } \\
\hline & $\begin{array}{l}\text { Normal value } \\
(n=397)\end{array}$ & $\begin{array}{l}\text { Moderately } \\
\text { increased }(n=1 \mid 6)\end{array}$ & $\begin{array}{l}\text { Severely } \\
\text { increased }(n=49)\end{array}$ & $\begin{array}{l}\text { Not measured } \\
(n=58)\end{array}$ & $\begin{array}{l}\text { Total } \\
(N=620)\end{array}$ & $P$-value \\
\hline Cardiac, n (\%) & $152(38.2)$ & $35(30.1)$ & $15(30.6)$ & $24(4 \mid .4)$ & $226(36.5)$ & 0.275 \\
\hline Respiratory, n (\%) & $4 I(10.3)$ & $13(11.2)$ & $4(8.1)$ & $7(12.1)$ & $65(10.4)$ & 0.916 \\
\hline Renal, n (\%) & $28(7)$ & $4(3.4)$ & $3(6.1)$ & $3(5.2)$ & $38(6.1)$ & 0.546 \\
\hline Infectious, n (\%) & $17(4.2)$ & $6(5.2)$ & $2(4.1)$ & $2(3.4)$ & $27(4.4)$ & 0.957 \\
\hline $\begin{array}{l}\text { Unclosed sternum/bleeding } \\
\text { control surgery, } \mathrm{n}(\%)\end{array}$ & $21(5.2)$ & $7(6)$ & $3(6.1)$ & $3(5.2)$ & $34(5.5)$ & 0.986 \\
\hline Neurologic, n (\%) & $24(6)$ & $8(6.8)$ & $0(0)$ & $3(5.2)$ & $35(5.6)$ & 0.332 \\
\hline Miscellaneous, n (\%) & $18(4.5)$ & $4(3.4)$ & $5(10)$ & $6(10.3)$ & $33(5.3)$ & 0.089 \\
\hline $\begin{array}{l}\text { Long ICU or hospital stay } \\
\text { period, } n(\%)\end{array}$ & $101(25.4)$ & $26(22.4)$ & $26(53.1)^{* * *}$ & $19(32.8)$ & $172(27.7)$ & 0.018 \\
\hline Overall complication rate, $\mathrm{n}(\%)$ & $219(55.2)$ & $59(50.9)$ & $32(65.3)$ & $35(60.3)$ & $345(55.6)$ & 0.323 \\
\hline Mortality, n (\%) & $35(8.8)$ & $5(4.3)$ & $2(4.1)$ & $3(5.17)$ & $45(7.3)$ & 0.257 \\
\hline
\end{tabular}

Notes: *Normal value: ESR value $<15 \mathrm{~mm} / \mathrm{h}$ or $<20 \mathrm{~mm} / \mathrm{h}$ in female or male patients, respectively; moderately increased: ESR value $<40 \mathrm{~mm} / \mathrm{h}$; severely increased: ESR value $\geq 40 \mathrm{~mm} / \mathrm{h}$. ${ }^{* *}$ The rate of the long ICU or hospital stay was higher in severely increased ESR group than normal value or moderately increased groups $(P$-value, $0.00 \mathrm{I})$. Abbreviations: ESR, erythrocyte sedimentation rate; ICU, intensive care unit.

Table 4 The relationship between postoperative morbidity and mortality rate with various CRP levels

\begin{tabular}{|c|c|c|c|c|c|}
\hline \multirow[t]{2}{*}{ Complication } & \multicolumn{5}{|l|}{ CRP groups } \\
\hline & $\begin{array}{l}\text { Normal } P \text {-value } \\
(0-5 \mathrm{mg} / \mathrm{L}), \mathrm{n}=372\end{array}$ & $\begin{array}{l}\text { Mildly increased } \\
(5-40 \mathrm{mg} / \mathrm{L}), \mathrm{n}=17\end{array}$ & $\begin{array}{l}\text { Moderately increased } \\
(40-200 \mathrm{mg} / \mathrm{L}), \mathrm{n}=14\end{array}$ & $\begin{array}{l}\text { Severely increased } \\
(>200 \mathrm{mg} / \mathrm{L}), n=39\end{array}$ & $P$-value \\
\hline Cardiac, n (\%) & $128(34.4)$ & $8(47.1)$ & $6(42.9)$ & $18(46.2)$ & $>0.05$ \\
\hline Respiratory, n (\%) & $35(9.4)$ & $2(11.8)$ & I (7.I) & $8(20.5)$ & $<0.05^{*}$ \\
\hline Renal, n (\%) & $17(4.5)$ & I (5.9) & $2(14.3)$ & $5(12.8)$ & $<0.05^{*}$ \\
\hline Infectious, n (\%) & $13(3.4)$ & $0(0)$ & I (7.I) & $8(20.5)$ & $<0.05^{*}$ \\
\hline Bleeding or unclosed sternum, $\mathrm{n}(\%)$ & $14(3.8)$ & I (5.9) & I (7.I) & $5(12.8)$ & $<0.05^{*}$ \\
\hline Neurologic, n (\%) & $22(5.9)$ & I (5.9) & I (7.I) & $2(5.1)$ & $>0.05$ \\
\hline Miscellaneous, n (\%) & $18(4.8)$ & I (5.9) & I (7.I) & $2(5.1)$ & $>0.05$ \\
\hline Complications (all types), n (\%) & $137(36.8)$ & $9(52.9)$ & $5(35.7)$ & $22(56.4)$ & $<0.05^{*}$ \\
\hline Mortality, n (\%) & $15(4 \%)$ & I (5.9) & I (7.I) & $6(15.4)$ & $<0.05^{*}$ \\
\hline Ventilatory support (hours) & $20.2 \pm 1.3$ & $20.6 \pm 5.5$ & $20.1 \pm 7.9$ & $24.3 \pm 5.9$ & $<0.05^{*}$ \\
\hline ICU stay (days) & $4.5 \pm 0.2$ & $4.2 \pm 0.7$ & $5.0 \pm 1.4$ & $5.7 \pm 3.5$ & $<0.05^{*}$ \\
\hline Hospital stay (days) & $8.4 \pm 0.3$ & $7.5 \pm I .1$ & $6.6 \pm 0.8$ & $9.1 \pm 3.1$ & $<0.05^{*}$ \\
\hline
\end{tabular}

Notes: *Significant differences between severely increased CRP group with other groups. ESR was not different in various preoperative CRP levels.

Abbreviations: CRP, C-reactive protein; ICU, intensive care unit; ESR, erythrocyte sedimentation rate. 
levels. In general, morbidity and mortality rates were high when CRP was severely increased.

\section{Discussion}

The present study was conducted primarily to evaluate the relationship between elevated preoperative ESR and postoperative morbidity and mortality in elective adult cardiac surgery. The role of preoperative ESR in preoperative subspecialty consultation rate and postponing of the elective surgery was also investigated. Optimizing the patients' health status, preoperatively, is the main indispensible responsibility of a surgical team. Such efforts have to be cost-effective, facile and safe. In this regard, any surgical team has to collect any data related to patients' health status. They must decide what data may ensure clinical significance in patient postoperative outcome. Hence, the paraclinical examinations have been done. Simply put, the team has to consider the sensitivity value of any test. Applicable to various diseases, ESR measurement is not a specific test. ${ }^{13,14}$ ESR commonly is increased in any disease where there is a certain degree of inflammation. As a matter of fact, ESR primarily indicates the plasma concentration of abnormal protein or proteins pertinent to inflammation. There exists controversy regarding the advantages of measuring preoperative ESR levels (for optimizing patients' preoperative conditions) prior to cardiac surgery. Natali et al ${ }^{15}$ demonstrated that even a slight increase in ESR levels is a risk factor for mortality due to coronary artery disease in male patients. Manchon et al ${ }^{16}$ (1988) reported the high recurrence of issues (95\%) such as infection, malignancy and inflammation in patients with ESR levels $>70 \mathrm{~mm} / \mathrm{h}$. Yayan ${ }^{17}$ showed that ESR usually is high in patients with coronary heart disease, and this may be due to the inflammatory etiology of coronary heart disease. Togan et $\mathrm{al}^{7}$ similarly demonstrated that in male patients who had undergone $\mathrm{CABG}$ surgery, the elevated preoperative ESR can bring about midterm postoperative adverse events such as morbidity and mortality. Togan et al stated that ESR, as a routine test, should be measured preoperatively in patients undergoing CABG surgery; any patient with high ESR should be examined in detail for the purpose of preempting mortality and morbidity.

A total of 105 subspecialty consultations were given to 79 patients where only five consultations were due to elevated ESR. The consultations did not end in any improved outcome or specific fruition. It is patent that elevated preoperative ESR did not help the medical team to identify unknown diseases or optimize the preoperative status. Nevertheless, surgery was temporarily deferred in only 20 patients. The mortality rate was generally high in the consulters, hence the fact that they were at high risk. There is general agreement that ESR measurement is a nonspecific test, yet theoretically, the next step must be making use of other specific tests in search for a definitive diagnosis. The present research demonstrated that, usually, the next step is unfruitful and probably unnecessary; however, it must be considered that at certain points where ESR is significantly augmented it can affect some aspects of the outcome (increased ICU and hospital stay time). In comparison with ESR, CRP is more specific, ${ }^{18}$ and the amount of increase in CRP levels is more directly correlated with the severity of infection or inflammation. ${ }^{19}$ Accordingly, there is agreement that preoperative increase in CRP levels generally augments the risk of mortality and morbidity, which was the case in our study. The present finding is contradictory to that of Gaudino et al's study, ${ }^{20}$ yet corroborates the results of Choi et al, Biancari et al and Cappabianca et al concerning the relationship between increased CRP and postoperative complications. ${ }^{21-24}$ ESR measurement has not been specifically applied to the prediction of postoperative complications. Mönig et $\mathrm{al}^{4}$ showed that measuring ESR is not an appropriate test for screening. Moreover, they advocated that elevated ESR level is not a proper yardstick for costly cancer diagnostic tests in patients with no symptoms of cancer. They also recommended that it is better to use ESR in conjunction with clinical findings in order to monitor the disease activity. ${ }^{4}$ Despite the fact that clinical findings are the most valuable data, it should be noted while using these tests that CRP is preferable to ESR. ${ }^{25}$ Arribas-Leal et $\mathrm{al}^{26}$ reported that no recognizable association exists among CRP, acute myocardial infarction (AMI) and postoperative mortality rate. Sahin et $\mathrm{al}^{27}$ reported that preoperative CRP does not have any correlation with complications such as early renal dysfunction. Given the obtained results, only in limited cases high preoperative ESR levels resulted in specialty consultation; in almost all of these cases, the cause of consultation was other reasons that were not conducive to diagnosing new diseases. Overall, preoperative high ESR did not delay the surgery. Although preoperative high ESR did not have any impact on overall postoperative morbidity and mortality rate, it did augment ICU and hospital stay time. In summary, it seems that ESR is not a useful predictive parameter for postoperative morbidity and mortality and cannot play a positive role in the diagnosis of new or unknown diseases or help optimize preoperative conditions. Also in our investigation, the total number of the patients was high, only relatively a few percentage of the patients $(7.9 \%)$ had severely high ESR that may expose 
the study to important limitations. However, if we consider all the patients with moderately or severely increased ESR in a single study group, the total number of patients with an ESR $>20 \mathrm{~mm} / \mathrm{h}$ is comparable to that of the Tugan study. ${ }^{7}$

\section{Conclusion}

We found that elevated preoperative ESR does not cause canceling or postponing of the surgery, nor does it help diagnose a new previously undiagnosed disease. In general, elevated preoperative ESR does not affect postoperative morbidity or mortality rates; however, in cases of increased to $>40 \mathrm{~mm} / \mathrm{h}$, it can augment the need for long period of ICU and hospital stays, postoperatively. It appears that routine preoperative ESR measurement in heart surgery candidates does not conduce to the prediction of postoperative complications or mortality rate, nor can it play any major part in optimizing the preoperative status.

\section{Acknowledgments}

This study was supported by cardiovascular research center of Tabriz University of Medical Sciences. This study was done in conjunction with another study that was done for investigating the role of the abnormal preoperative CRP level in postoperative mortality and morbidity rate in elective adults' cardiac surgery.

\section{Disclosure}

The authors report no conflicts of interest in this work.

\section{References}

1. Ferrando A, Ivaldi C, Buttiglieri A, et al. Guidelines for preoperative assessment: impact on clinical practice and costs. Int J Qual Health Care. 2005;17(4):323-329.

2. Barnard NA, Williams RW, Spencer EM. Preoperative patient assessment: a review of the literature and recommendations. Ann R Coll Surg Engl. 1994;76(5):293.

3. Bryson GL, Wyand A, Bragg PR. Preoperative testing is inconsistent with published guidelines and rarely changes management. Can J Anaesth. 2006;53(3):236-241.

4. Mönig H, Marquardt D, Arendt T, Kloehn S. Limited value of elevated erythrocyte sedimentation rate as an indicator of malignancy. Fam Pract. 2002;19(5):436-438.

5. Johansson H-E, Haenni A, Zethelius B. Changes in erythrocyte sedimentation rate, white blood cell count, liver enzymes, and magnesium after gastric bypass surgery. J Obes. 2011;2011:273105.

6. Rashidi F, Jamshidi P, Kheiri M, et al. Is leukocytosis a predictor for recurrence of ischemic events after coronary artery bypass graft surgery? A cohort study. ISRN Cardiol. 2012;2012:824730.

7. Togan T, Günday M, Çiftçi Ö, Bingol H. Can preoperative erythrocyte sedimentation rate serve as an indicator for midterm adverse events after coronary bypass grafting? Heart Surg Forum. 2015;18(2):E047-E52.
8. Gillum RF, Mussolino ME, Makuc DM. Erythrocyte sedimentation rate and coronary heart disease: the NHANES I Epidemiologic Follow-up Study. J Clin Epidemiol. 1995;48(3):353-361.

9. Andresdottir MB, Sigfusson N, Sigvaldason H, Gudnason V. Erythrocyte sedimentation rate, an independent predictor of coronary heart disease in men and women the Reykjavik Study. Am J Epidemiol. 2003;158(9):844-851.

10. Ozlu MF, Şen N, Karakas MF, et al. Erythrocyte sedimentation rate in acute myocardial infarction as a predictor of poor prognosis and impaired reperfusion. Med Glas (Zenica). 2012;9(2):189-197.

11. Erikssen G, Liestøl K, Bjørnholt J, Stormorken H, Thaulow E, Erikssen J. Erythrocyte sedimentation rate: a possible marker of atherosclerosis and a strong predictor of coronary heart disease mortality. Eur Heart J. 2000;21(19):1614-1620.

12. Parolari A, Poggio P, Myasoedova V, et al. Biomarkers in coronary artery bypass surgery: ready for prime time and outcome prediction? Front Cardiovasc Med. 2015;2:39.

13. Osei-Bimpong A, Meek J, Lewis S. ESR or CRP? A comparison of their clinical utility. Hematology. 2007;12(4):353-357.

14. Sokka T, Pincus T. Erythrocyte sedimentation rate, C-reactive protein, or rheumatoid factor are normal at presentation in $35 \%-45 \%$ of patients with rheumatoid arthritis seen between 1980 and 2004: analyses from Finland and the United States. J Rheumatol. 2009;36(7): 1387-1390.

15. Natali A, L'Abbate A, Ferrannini E. Erythrocyte sedimentation rate, coronary atherosclerosis, and cardiac mortality. Eur Heart $J$. 2003;24(7):639-648.

16. Manchon N, Poutrain J, Senant J, Cottin B, Bercoff E, Bourreille J. [Diagnostic value of a distinct rise in sedimentation rate]. Presse Med. 1988;17(18):905-907.

17. Yayan J. Erythrocyte sedimentation rate as a marker for coronary heart disease. Vasc Health Risk Manag. 2012;8:219-223.

18. Gabay C, Kushner I. Acute-phase proteins and other systemic responses to inflammation. N Engl J Med. 1999;340(6):448-454.

19. Black S, Kushner I, Samols D. C-reactive protein. J Biol Chem. 2004;279(47):48487-48490.

20. Gaudino M, Nasso G, Andreotti F, et al. Preoperative C-reactive protein level and outcome following coronary surgery. Eur J Cardiothorac Surg. 2002;22(4):521-526.

21. Choi J-H, Cho DK, Song Y-B, et al. Preoperative NT-proBNP and CRP predict perioperative major cardiovascular events in non-cardiac surgery. Heart. 2010;96(1):56-62.

22. Biancari F, Lahtinen J, Lepojärvi S, et al. Preoperative C-reactive protein and outcome after coronary artery bypass surgery. Ann Thorac Surg. 2003;76(6):2007-2012.

23. Cappabianca G, Paparella D, Visicchio G, et al. Preoperative C-reactive protein predicts mid-term outcome after cardiac surgery. Ann Thorac Surg. 2006;82(6):2170-2178.

24. Eissa B, Solmaz F, Haleh F, et al. The association between preoperative plasma C-reactive protein (CRP) level and postoperative adult heart surgery outcome. Open J Int Med. 2016;6(3):93.

25. Crowson CS, Rahman MU, Matteson EL. Which measure of inflammation to use? A comparison of erythrocyte sedimentation rate and C-reactive protein measurements from randomized clinical trials of golimumab in rheumatoid arthritis. $J$ Rheumatol. 2009;36(8): 1606-1610.

26. Arribas-Leal JM, Pascual-Figal DA, Tornel-Osorio PL, RuipérezAbizanda JA, Valdés-Chavarri M, Arcas-Meca R. Prognostic role of new biomarkers in off-pump coronary artery bypass surgery. Rev Esp Cardiol. 2006;59(3):280-283.

27. Sahin V, Akpinar MB, Sevim E, et al. Preoperative CRP levels is not predictive early renal dysfunction after coronary artery bypass surgery. Int J Clin Exp Med. 2015;8(3):4146. 
The International Journal of General Medicine is an international, peer-reviewed open-access journal that focuses on general and internal medicine, pathogenesis, epidemiology, diagnosis, monitoring and treatment protocols. The journal is characterized by the rapid reporting of reviews, original research and clinical studies across all disease areas.
The manuscript management system is completely online and includes a very quick and fair peer-review system, which is all easy to use. Visit http://www.dovepress.com/testimonials.php to read real quotes from published authors. 